\title{
El paso del tiempo y el recuerdo del pasado en el antiguo Egipto
}

\author{
JOSÉ MANUEL GALÁN \\ Instituto de Filología. CSIC. Madrid
}

\section{RESUMEN}

En el antiguo Egipto existían dos percepciones distintas, pero complementarias, sobre el paso del tiempo: una cíclica, propia de un contexto religioso, y otra lineal, propia de un contexto laico o civil. Pero ambas percepciones implicaban una constante mirada hacia el pasado, bien por considerarlo un modelo a seguir en el presente, o bien por tomarlo como referencia para su superación irreversible. El uso político de la historia contribuyó mucho a mantener vivo, a la vez que transformar, el pasado en el presente; como lo hizo la conveniencia personal en los relatos autobiográficos y hasta en obras de ficción. Ante tanto recurso al pasado y a la historia, puede uno preguntarse por qué entonces no surgió en Egipto la historiografía. La respuesta pudiera estar en que la sociedad no la necesitaba, ya que precisamente vivía rodeada de textos históricos, dotados además de instrumentos propios de veracidad.

Palabras clave: Tiempo religioso, Tiempo civil, Historia política, Listas de reyes, Textos autobiográficos, Obras de ficción, Historiografía.

\section{SUMMARY}

In Ancient Egypt one finds two different yet complementary perceptions of the passage of time: one cyclical, characteristic of a religious context, the other linear, distinctive of a secular, civil context. However, both perceptions implied a permanent look onto the past, either because it was taken as a model for the present or because it was regarded as a standard that needed to be surpassed. The political use of history did much for keeping, and transforming, the past in the present; as did personal convenience when it came to autobiographical narratives and even the composition of works of fiction. Given this major concern for the past and for history, one might ask why then history as a scholarly discipline failed to emerge in the land of the Pharaohs? The answer to this question might be that Egyptian society felt no need for such scholarly endeavor, precisely because it developed surrounded by historical texts, which even included instruments to check on their truthfulness.

Key words: Religious Time, Secular Time, Political History, Lists of Kings, Autobiographical Texts, Works of Fiction, History as a Scholarly Discipline.

RDTP, LIX, 1 (2004): 37-55 
La percepción del tiempo es y ha sido desde antiguo una sensación subjetiva, sujeta a múltiples factores. El paso del tiempo, por mucho que se empeñen en definirlo los individuos y los distintos grupos y culturas que han existido y existen, por mucho que lo cuantifiquen, subdividan y calculen, es, efectivamente, un valor relativo.

En el antiguo Egipto, desde los comienzos de su historia, allá por el año 3000 a. C., convivían dos percepciones bien distintas y casi excluyentes sobre el transcurrir del tiempo. Como en tantos otros aspectos de la cultura egipcia ${ }^{1}$, las distintas percepciones de una misma realidad no compiten entre sí, sino que tienen la finalidad de complementarse unas a otras para cubrir los múltiples aspectos de una realidad compleja como es, en este caso, la percepción del paso del tiempo. Es el momento y el lugar en el que se encuentra un individuo, sus circunstancias, su contexto, lo que le hará percibir el tiempo, bien como un "eterno retorno" (Serrano 2001) - es decir, como un ciclo que se repite periódicamente- o bien como una línea que avanza hacia el infinito y en la que cada momento es original y distinto a todos los demás.

\section{CONCEPCIÓN CÍCLICA DEL PASO DEL TIEMPO}

Los antiguos egipcios observaron que los cambios que se efectuaban en la naturaleza seguían unas pautas cíclicas. Los astros del cielo, la vegetación, la inundación del Nilo, etc., experimentaban un continuo desaparecer para volver a aparecer después, ocultarse para volver a salir, morir para revivir. En el hombre, los cambios o transformaciones cíclicas se aprecian de una forma menos obvia. Es, tal vez, en el ámbito del deseo donde el hombre liga su existencia al retorno a una etapa anterior desaparecida, alimentando la esperanza de que tras su muerte física volverá a nacer en el Más Allá, en una especie de paraíso donde todo seguirá siendo como idílicamente era antes. Por ello, la concepción cíclica del tiempo aparece reflejada en textos de carácter funerario y religioso, y muy rara vez en inscripciones conmemorativas de tipo laico o político ${ }^{2}$.

\footnotetext{
${ }^{1}$ Como puede ser el carácter divino y a la vez humano del faraón, o el lugar donde vivirán las personas después de su muerte física, si en el cielo (acompañando al sol o junto a las estrellas imperecederas) o bajo tierra.

${ }^{2}$ El carácter cíclico del tiempo está muy presente en todo lo que atañe a la monarquía, pero ello tiene más que ver con el carácter ritual y religioso de la institución que con el aspecto humano del rey.
} 


\section{CONCEPCIÓN LINEAL DEL PASO DEL TIEMPO}

La percepción del transcurrir del tiempo como una línea recta que avanza continuamente hace que el ser humano se distancie inexorablemente de sus antepasados, de las acciones y modos del pasado. El olvido del pasado se convierte así en una continua amenaza, que los egipcios combatían con el ejercicio de la memoria, apoyándose en la tradición oral y en las inscripciones grabadas en piedra.

La valoración del pasado también variaba según el contexto. Por un lado, en ocasiones primaba el pensamiento de que "cualquier tiempo pasado fue mejor", pero no el ayer, sino el pasado lejano; cuanto más remoto, más modélico era. Otras veces, el ayer era percibido como susceptible de ser mejorado, y se presentaba el tiempo presente e incluso el futuro como una superación de la etapa anterior.

\section{EL CONTEXTO RELIGIOSO}

En un contexto religioso, el origen y la tradición eran exaltados, recordados y emulados constantemente: es en los primeros momentos, en el comienzo, donde se encuentra el estado perfecto de las cosas. El paso del tiempo lo único que produce es que las objetos se deterioren y las ideas y modos de actuar se desvirtúen. Los textos hacen referencia al origen con la fórmula $s p t p i$, "la primera vez", y aluden al comienzo de los tiempos con la expresión "en el tiempo/época de Ra" o "en el tiempo/época de Horus", pues se creía que al comienzo de la existencia vivieron y reinaron los dioses sobre la tierra (Baines 1989).

Uno de los aspectos más interesantes del famoso Papiro de Turín (Gardiner 1959), compuesto en torno al año 1200 a. C., es que antes de mencionar al primer rey de Egipto, llamado Meni (= Narmer), el texto hace referencia a una serie de divinidades que supuestamente habían ejercido la realeza sobre la tierra antes que los hombres. Sus nombres fueron escritos dentro de los característicos "cartuchos reales": Geb, Osiris, Seth, Horus, Tot, Maat, etc. (véase fig. 1). Según el autor del papiro, Horus había reinado al menos 300 años y Tot lo había hecho durante 7.726 años. Después de las divinidades, el texto continúa haciendo referencia a los reinados de una serie de "espíritus", entre los que se encuentran los legendarios "seguidores de Horus". El listado de los reyes humanos de Egipto comienza sin ningún tipo de interrupción o señal que los separe de la etapa "divina" anterior. Así, en un texto de carácter supuestamente práctico, originado probablemente en un contexto administrativo, la recogida por escrito de la realidad deja sitio a la mitología, y es 


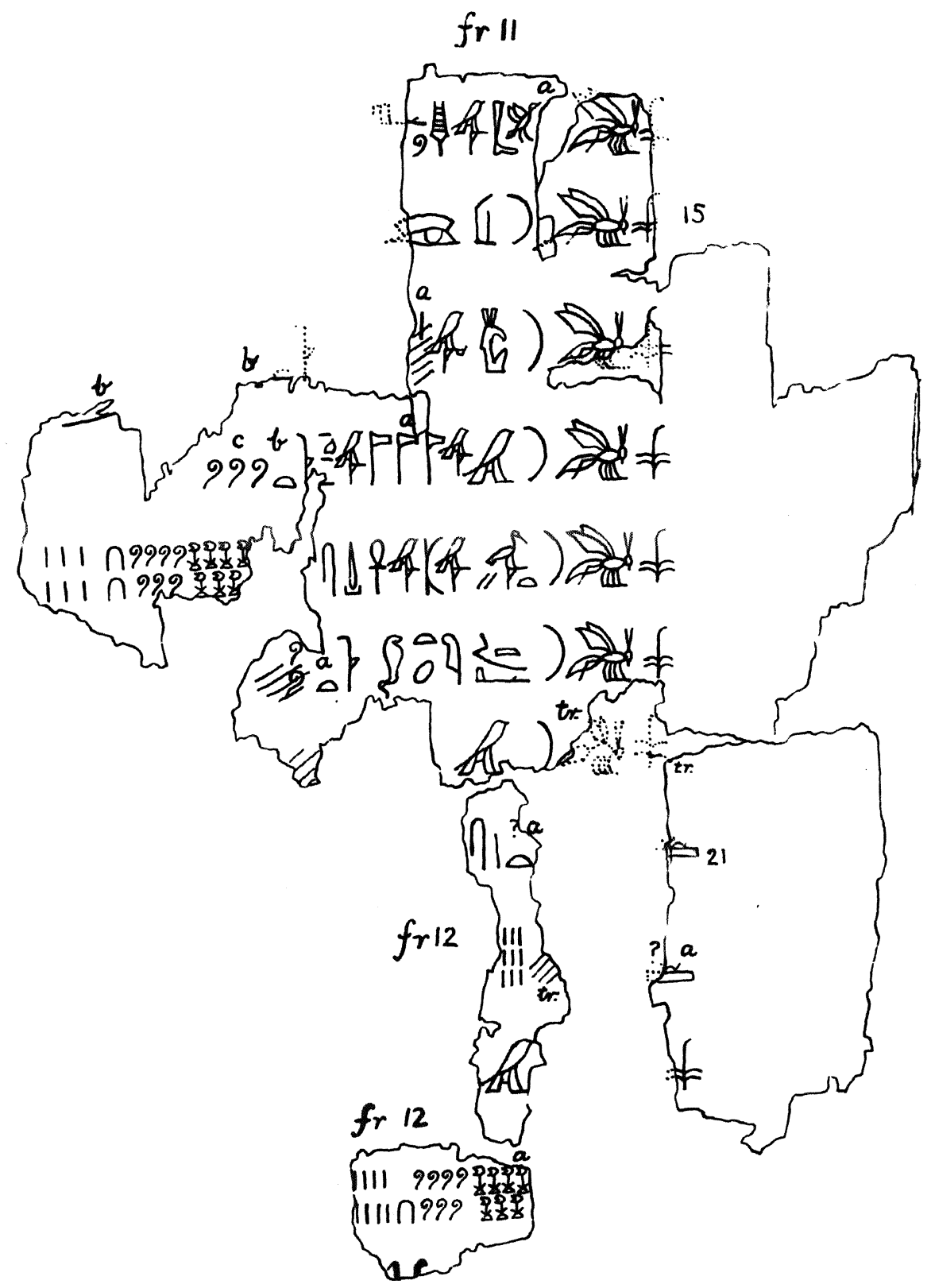

Figura 1.-Papiro de Turín. Comienzo del listado de reyes de Egipto, mencionando el reinado de los dioses Osiris, Seth, Horus, Tot, Maat, etc. 
que historia y mitología e historia y ficción no eran conceptos antagónicos ni excluyentes en el antiguo Egipto.

Una inscripción conmemorativa de la dinastía XVIII hace referencia a las campañas que, en torno al año 1450 a. C., el rey Tutmosis III llevó a cabo por Siria-Palestina, diciendo (Helck 1955: 1246):

Cada vez que Su Majestad regresaba, habiendo sucedido su ataque con valor y victoria (es decir, habiendo vencido), él hacía que Egipto fuera como cuando Ra estaba en él como rey $[\ldots]^{3}$.

La narración mítica más antigua conservada en Egipto, la "Destrucción (parcial) de la humanidad", fechada en torno al año 1300 a. C., ha llegado hasta nosotros en tres versiones, escritas sobre las paredes de las tumbas de los reyes Seti I, Ramsés II y Ramsés III (Maystre 1941, Hornung 1982). Sin embargo, el hecho de que la lengua utilizada en las redacciones sea "egipcio clásico" (versus "neo-egipcio") permite suponer que el texto tuvo su origen en una época anterior, poco después del año 2000 a. C. El comienzo sitúa la acción al comienzo de los tiempos, cuando los dioses reinaban sobre la tierra:

Ocurrió [en los tiempos] de Ra, quien se creó a sí mismo, cuando era rey de los hombres y de los dioses a la vez. Los hombres comenzaron a confabular contra Ra. Por entonces, Su Majestad - qque viva, prospere y tenga salud!- era ya un anciano, sus huesos eran de plata, su cuerpo de oro y su pelo de verdadero lapislázuli. Estando Ra meditando sobre la confabulación de los hombres, Su Majestad -ique viva, prospere y tenga salud! - dijo a los dioses que le acompañaban: ... ${ }^{4}$.

Para acceder y conocer el pasado - cuando las cosas eran supuestamente como debían ser-, la consulta de los libros en las bibliotecas o archivos de los templos era el mejor recurso (Schott 1990). El texto elaborado por los sacerdotes de la ciudad de Menfis sobre la creación del cosmos, por ejemplo, se conserva en una inscripción grabada en una losa de piedra ${ }^{5}$ durante el reinado de Shabaka (712-698 a. C.). A pesar de que los principales aspectos de la "teología menfita" aparecen reflejados en textos 1500 años antes, en los denominados "Textos de las pirámides", el esfuerzo conservador y restaurador de este faraón de origen cushita (= sudanés) hizo posible que haya llegado hasta nosotros una versión narrada (Diego Espinel 2004). La inscripción comienza informando sobre lo siguiente:

\footnotetext{
${ }^{3}$ Las palabras entre paréntesis no pertenecen al texto que se traduce, pero son necesarias en la traducción para que el texto tenga sentido en la lengua moderna.

${ }^{4}$ Las palabras entre corchetes son reconstrucciones del texto en partes dañadas.

${ }^{5}$ Museo Británico 489.
} 
Entonces, Su Majestad copió este documento nuevamente en la casa de su padre (el dios) Ptah-al-sur-de-su-muralla. He aquí que Su Majestad lo encontró como sus antecesores lo hicieron, (pero) estando devorado por los gusanos. (Así,) no se conocía (completamente) de principio a fin. [Su Majestad hizo entonces que se copiara] de nuevo, quedando éste mejor que como estaba antes, para que su nombre (Shabaka) perdurara...

Una estela en el templo de Osiris en Abidos $^{6}$, erigida por un rey llamado Neferhotep (ca. 1600 a. C.), informa de la existencia y consulta de documentos relacionados con el culto, con el fin de conocer y recuperar la manera de hacer las cosas en el pasado, pues se entendía que ésa era la forma correcta (Helck 1975):

Su Majestad se dirigió a los nobles, a los cortesanos, a su séquito, a los escribas de jeroglíficos ${ }^{7}$ y a los encargados de todo lo reservado: "Es mi deseo ver los libros (más) antiguos, (de la época) de Atum. Abrid para mí el gran archivo. Dejadme conocer la apariencia de la divinidad, la forma de los dioses, (para que así) yo pueda realizar ofrendas divinas, abastecer los altares. (Dejadme) que yo conozca a Dios físicamente y pueda moldearle como era en un principio (...).

Los cortesanos respondieron: "Lo que tu $k a$ ordena es lo que sucede, oh soberano, mi señor. Prosiga Su Majestad a la biblioteca y vea Su Majestad todos los jeroglíficos".

Fue Su Majestad a la biblioteca y, cuando abrió los libros junto con los cortesanos, encontró los libros del templo de Osiris-primero-de-los-occidentales, señor de Abidos.

Su Majestad les dijo a los cortesanos: "Mi Majestad salvaguardará a mi padre Osiris-primero-de-los-occidentales, señor de Abidos. Le moldearé junto a su Eneada (= agrupación de dioses) como he observado en sus libros, con apariencia de rey de Egipto surgiendo del vientre de Nut".

Las "Instrucciones para el rey Merikaré" ${ }^{2}$ (ca. 2100 a.C.) incluyen al comienzo un consejo sobre el valor de la sabiduría; ésta se adquiría prestando atención a los antecesores, a la tradición, la cual se conserva recogida en los libros (Helck 1977, Quack 1992):

Sigue a tus padres, a tus ancestros [...]. Sus palabras están en los libros. Ábre(los) y lee, sigue al conocimiento. (Incluso) el artesano se convertirá en sabio.

\section{EL CONTEXTO CIVIL}

Si bien en un contexto religioso se ha de volver la vista atrás para hallar lo modélico, en un contexto laico o civil se ensalzaban los éxitos presentes

\footnotetext{
${ }^{6}$ Museo de El Cairo $J d^{\prime} E 35256$.

7 Literalmente "palabras de la divinidad."

${ }^{8}$ Papiro San Petesburgo 1116A, III 11- IV 1.
} 
sobre los del pasado. En la vida cotidiana, profesional y política, cada individuo, cualquiera que fuera su ocupación, se afanaba por superar a sus antecesores, por que sus acciones fueran más lejos o resultaran ser más perfectas que las que le habían servido a él de guía. Así, Sesostris III (ca. 1750 a.C.) levantó dos estelas gemelas ${ }^{9}$ junto a la Segunda catarata del Nilo, límite meridional de su autoridad, cuya inscripción comienza reflejando el afán del rèy por consolidar y superar lo realizado por sus predecesores (Janssen 1953, Eyre 1990, Parkinson 1991).

Año dieciséis, tercer mes de la estación Peret: estableciendo Su Majestad la frontera sur hasta Heh (= Semna). He establecido mi frontera habiendo sobrepasado río abajo a mis predecesores. He superado lo que se me había encomendado. Yo soy el rey, quien habla y actúa; lo que mi corazón concibe es lo que acontece por medio de mi acción...

\section{LA CONSTANTE MIRADA AL PASADO}

Pero tanto si el pasado (remoto) se percibía como un momento idílico, perfecto, como si el pasado (reciente) se percibía como un momento en el que las cosas eran susceptibles de ser mejoradas, los antiguos egipcios miraban constantemente hacia atrás. Eran conscientes de que para entender su realidad debían conocer el pasado, pues el estado de las cosas en el momento presente era consecuencia de la situación anterior. En cualquier aspecto de la vida, el pasado daba sentido al presente. De ahí el interés de los individuos por "recordar" su pasado. Esta mirada retrospectiva, entre otras razones, dio origen al género autobiográfico (Assmann 1983, Gnirs 1996) así como al interés de los individuos por mencionar o representar a sus ancestros en inscripciones y relieves, sobre todo dentro de un contexto funerario.

La finalidad de las inscripciones autobiográficas emplazadas dentro de las tumbas, y en casos excepcionales en templos, era dotar al individuo de un curriculum que le sirviera de argumento y justificación para superar su juicio final y acceder así a una vida eterna en el Más Allá. Por otro lado, como la vida del individuo en cuestión se consideraba ejemplar, se grababa en piedra para que resistiera el paso del tiempo, para que fuera recordada y pudiera así influir también sobre las generaciones venideras ${ }^{10}$.

Generalmente, las referencias genealógicas en las inscripciones autobio-

9 Berlín 1157.

${ }^{10}$ Sobre la posibilidad de aprender de experiencias pasadas (asumiendo que pueden surgir situaciones similares con el paso del tiempo), o que, por el contrario, cada situación es única y, por tanto, las experiencias pasadas no sirven para aprender, véase Vernus (1995). 
gráficas o en las escenas en relieve o pintura que decoran las paredes interiores de las tumbas se ciñen a la mención del nombre del padre y de la madre, no pocas veces acompañada por la representación de ambos compartiendo un banquete funerario. En algunos casos, la narración de las acciones llevadas a cabo por el autor, narrador y protagonista del texto van precedidas por un breve excursus sobre una actividad del padre que, de alguna forma, explica e introduce lo que se narra a continuación.

Un fragmento de la extensa biografía de Harjuf (ca. 2250 a.C.) sirve para ilustrar este fenómeno (Sethe 1933: 123-27). La inscripción fue grabada en la fachada de su tumba, excavada en la falda de una colina en el distrito de Asuán, lugar hoy llamado Qubbet el-Hawa, y comienza diciendo:

\begin{abstract}
El portador del sello bit, amigo único, sacerdote lector, supervisor de intérpretes, el venerado ante Ptah-Sokar, Harjuf, dice: "La majestad del rey Merenra, mi Señor, me envió, junto con mi padre, amigo único y sacerdote lector, Iri, a la tierra de Yam (al sureste de Asuán), con el fin de abrir camino hacia esa tierra. Lo realicé en siete meses. Traje de allí toda clase de productos valiosos y exóticos, y fui recompensado enormemente por ello. Su Majestad me envió una segunda vez, yo solo, ...
\end{abstract}

La autobiografía del almirante Ahmose, inscrita poco antes del año 1500 a.C. sobre las paredes interiores de su tumba rupestre en el-Kab (Lepsius 1849-1859: III, 12; Sethe 1930: 1-10; Lichtheim 1973-1980: II, 12-15), comienza también haciendo alusión al servicio prestado por su padre a la Corona, mostrándose él como el continuador de una tradición y, al mismo tiempo, como alguien capaz de superar las acciones de su inmediato antepasado.

Yo crecí en la ciudad de Nejeb (= el-Kab), siendo mi padre un soldado del rey de Egipto Seqenenra - (santo) inocente- Baba hijo de Rainet era su nombre. En época del señor de las Dos Tierras Nebpehtira (= Ahmose) - (santo) inocente- hice de soldado en su lugar en el barco "El toro bravo". Yo era todavía un adolescente, no había tomado aún esposa y dormía en pañales.

Habiendo fundado ya una casa, fui tomado para el barco del norte debido a mi valentía. Seguía al soberano a pie cuando marchaba sobre su carro. Cuando la ciudad de Avaris era sitiada, fui un valiente de pie junto a Su Majestad ...

Las "Listas de reyes", es decir, la sucesión por orden cronológico de los nombres de una serie de monarcas que ocuparon el trono de Egipto en el pasado, están atestiguadas desde casi los comienzos de la historia en Egipto.

- En torno al año 3000 a. C., la impronta de un cilindro sello recoge por orden los nombres "Horus" de los cinco primeros reyes de la historia de Egipto: Narmer, Aha, Djer, Wadj y Den, seguidos por la mención a la reina madre Mer-Neith (Dreyer 1987: 36). 
- Un plato ceremonial hallado en la pirámide escalonada del rey Zoser, de la dinastía III (Lacau y Lauer 1959-61: 8-17), fue grabado con los nombres "nesut-biti" de los últimos cuatro reyes de la primera dinastía: Semty (= Den), Meribpen (= Adjib), Nebti-Semsu (= Semerkhet), Nebti-Kaa (= Kaa).

- Una pequeña estatuilla de granito, de $39 \mathrm{~cm}$. de altura, representando a un particular de rodillas y con las manos sobre sus muslos en actitud orante, de nombre Hetepdief, hijo de Meri-Yehuty, tiene grabado sobre el hombro derecho los nombres "Horus" de los tres primeros reyes de la dinastía II: Hetepsekhemuy, Raneb y Ninetcher, precedidos de la representación de un fénix sobre un piramideon. Por el estilo de la escultura, la pieza puede fecharse a finales de la dinastía III ${ }^{11}$.

- La famosa "Piedra de Palermo" (figura 2), que probablemente fuera inscrita en la dinastía $\mathrm{V}$, en torno al año 2300 a.C., recuerda los nombres de los reyes de Egipto desde el comienzo de la monarquía hasta entonces, y cada uno de los años transcurridos es nombrado por un evento sobresaliente que le caracteriza y por el nivel alcanzado por la crecida del Nilo (Wilkinson 2000).

La composición de listas con los nombres de reyes anteriores no tenía exactamente la función de recordar el pasado para ensalzarlo o para mostrar cómo había sido superado, sino que servía para conectar el presente con un determinado pasado y, así, legitimar una situación que pudiera ser cuestionada. Con las "Listas de reyes" el presente busca su razón de ser, su justificación, argumentando su vínculo con un pasado incuestionable, ya casi mitificado por el paso del tiempo.

\section{SELECCIÓN DEL PASADO EN FUNCIÓN DEL PRESENTE}

Una sociedad o un determinado grupo dentro de una sociedad, motivado por presiones externas o ambiciones internas, puede sentir la necesidad de construir una identidad común en un determinado momento. Por otro lado, el distanciamiento del pasado y su consiguiente olvido puede también motivar que, en un momento de crisis de identidad, una sociedad o un individuo emprenda la tarea de reconstruir su pasado.

En el siglo XII a.C. se observa un mayor énfasis en el culto a los ancestros (Demarée 1983) y las genealogías, tanto de los monarcas como de los particulares, se retrotraen más y más y reciben una mayor importancia. En una de

${ }^{11}$ Museo de El Cairo, J'E 34557. 


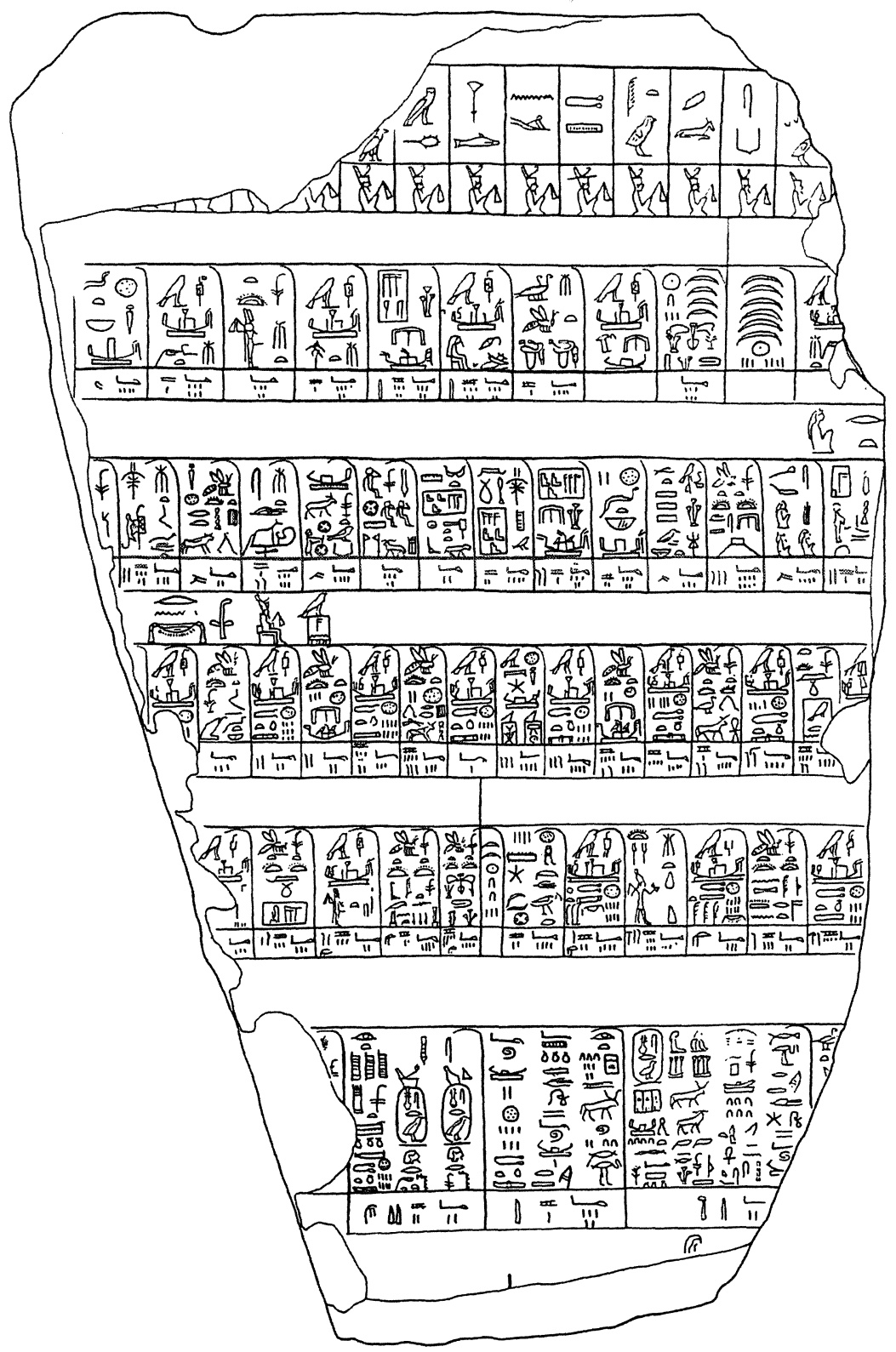

Figura 2.-Piedra de Palermo. Listado de los primeros reyes de Egipto, mencionando año por año un acontecimiento singular y la altura alcanzada por la crecida del Nilo. 
las salas del templo de Abidos dedicado al dios Osiris, el faraón Seti I, acompañado de su hijo, el príncipe y futuro rey Ramsés (II), se presenta ante una lista de los reyes de Egipto, desde el primero, Meni, hasta el propio Seti I, para ofrecerles las ofrendas típicas de los dioses y de los difuntos. En total son setenta y seis "cartuchos reales" con los nombres de los predecesores en el trono de Egipto. Pero la lista no está completa, pues numerosos reyes han sido omitidos, principalmente aquellos que habían reinado en periodos de crisis interna y división del territorio. También quedaron fuera los que eran considerados ilegítimos y/o heterodoxos, como fueron la reina Hatshepsut y el innovador religioso Akhenaton. A esta lista de reyes se suman otras inscritas en tumbas de particulares en Deir el-Medina (figura 3) y en Saqqara (Kemp 1989) y en el famoso Papiro de Turín, mencionado más arriba.

El hecho de que la mayoría de las listas ordene a los reyes en el correcto orden cronológico refleja la costumbre egipcia de mantener registrado en archivos todo lo que tuviera que ver de una forma $u$ otra con la administración y con la historia de la institución (Redford 1986). Por otro lado, la selección del pasado indica que cumplían una función política en el momento de su composición.

Cuando se alude al pasado en un escrito, el criterio para seleccionar a los personajes o los hechos que han de ser recordados depende de la intención del autor del texto, pues el autor siempre tiene una intención. La imagen que se puede ofrecer del pasado, igual que del presente, es siempre subjetiva. No existe el relato objetivo, pues el relato será siempre una descripción parcial de la realidad y, por tanto, inevitablemente subjetiva. Por ejemplo, los "anales" de las campañas conducidas por el rey Tutmosis III en Siria-Palestina, según reconoce la propia inscripción grabada sobre las pare-

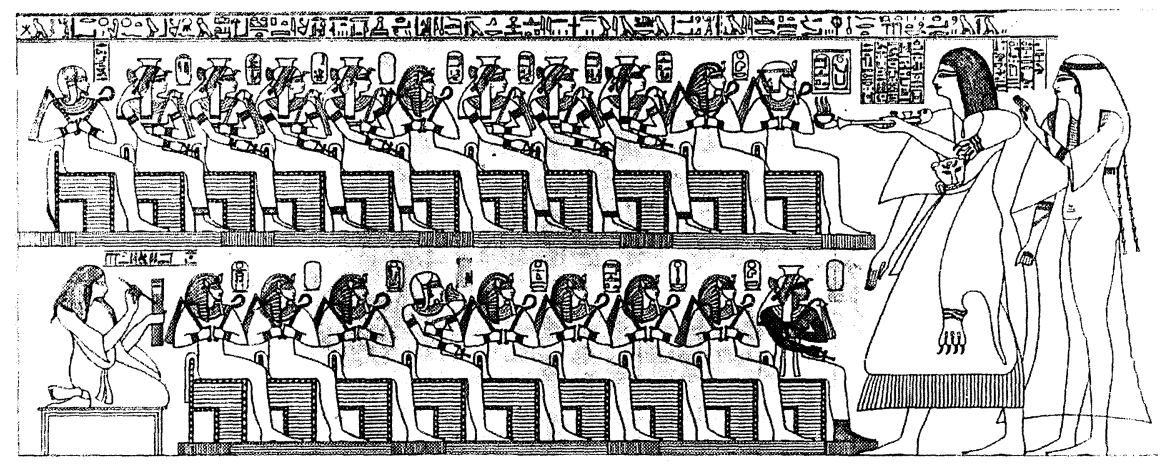

FIGURA 3.-Tumba de Inherkha en Deir el-Medina. El propietario, acompañado de su mujer, realiza una ofrenda de incienso ante los principales reyes de la antigua Tebas. 
des interiores del templo de Amón en Karnak, es tan sólo un extracto de un extenso informe escrito en cuero o papiro (Sethe 1930: 661-62 y 693):

En cuanto a todo lo que Su Majestad hizo a esta población (Megiddo), a aquel maldito enemigo junto con su maldita tropa, está registrado por cada uno de los días, el nombre de cada expedición, [el nombre] de cada capitán de infan[tería] [...(todo ello) es más numeroso que lo que se recoge escrito en esta inscripción], está recopilado en un rollo de cuero en el templo de Amón hasta la fecha.

De igual forma que pueden hacerse presentes personajes y hechos del pasado mediante su recuerdo, también se puede atentar contra la memoria de alguien o de algo, pretender que desaparezca su recuerdo, que su existencia desaparezca del pasado. Así, los egipcios concebían el olvido, el ignorar a alguien o el ignorar algo, como un arma contra los enemigos, aunque éstos formasen ya parte del pasado. Incluso en ocasiones el odio les conducía a borrar de la faz de la tierra cualquier resto de su existencia física. Este fenómeno se denomina comúnmente damnatio memoriae. El nombre y la figura de Hatshepsut fueron martilleados en los relieves de los templos, de su tumba y de las tumbas de sus oficiales veinte años después de que la reina hubiera muerto. Akhenaton fue condenado al olvido por su "herejía", pero también Tutankhamon, a pesar de haber sido quien volvió a la ortodoxia y reinstauró al dios Amón todos sus privilegios.

La práctica de la damnatio memoriae puede suscitar la pregunta de por qué molestarse en atentar contra alguien o contra algo que forma ya parte del pasado. La respuesta es, sin lugar a dudas, porque el pasado existe en el presente. Los antiguos egipcios, igual que muchas otras culturas antiguas y contemporáneas, no limitaban la existencia de alguien o de algo al tiempo que durase su actividad sobre la tierra; estaba ligada a su pervivencia en la memoria, pues el recuerdo de alguien o de algo posee la capacidad de ejercer algún tipo de influencia sobre una o más personas, que es en definitiva lo que caracteriza a la existencia.

\section{FABRICAR Y LEER HISTORIA}

La función de la escritura es, en gran medida, posibilitar la comunicación entre un emisor y un receptor que están físicamente distantes. El distanciamiento espacial entre emisor y receptor da origen a la correspondencia. El distanciamiento temporal entre emisor y receptor da lugar a una amplia gama de textos de carácter testimonial. El hecho de escribir algo supone, en la mayoría de los casos, la plena conciencia del paso del tiempo, es decir, de que lo que hoy es presente mañana será pasado.

Esto es todavía más evidente cuando se decide que un texto sea graba- 
do sobre un soporte no perecedero, como en principio es la piedra a diferencia del papiro. La función de las inscripciones sobre piedra es precisamente vencer el paso del tiempo y otorgarle al individuo la posibilidad de comunicarse con audiencias de otros momentos. Así, algunas de las inscripciones explícitamente señalan que el texto está dirigido a generaciones venideras, por lo que la intención del autor (directa o indirectamente, consciente o inconscientemente) es informar a esas generaciones futuras del pasado más o menos lejano (en el momento de la composición del texto, todavía el presente o pasado reciente). Es decir, que, además de celebrar y dedicar un acontecimiento, una inscripción conmemorativa tenía la pretensión de convertirse en el futuro en una fuente histórica.

La elaboración de una futura fuente histórica implica la presunción de que, en el futuro más o menos lejano, va a haber alguien interesado en el pasado, en leer sobre acontecimientos de otros tiempos, recuperarlos en el recuerdo o en la memoria y reconstruirlos, lo que supone un primer acercamiento a la Historia.

Pero las inscripciones del antiguo Egipto van todavía más allá, e incluyen en muchos casos la reiteración de que lo que se ha escrito es absolutamente verdad. Es decir, que el autor que construye una fuente histórica no sólo está asumiendo que alguien la leerá en el futuro para conocer un aspecto del pasado, sino incluso que el lector se cuestionará y podrá llegar a dudar de la autenticidad de los hechos narrados en la inscripción. La actitud del autor hacia el potencial lector de su texto está revelando así, indirectamente, la existencia del lector crítico de las fuentes históricas; esto es, está constatando la existencia de "historiadores primarios" ${ }^{12}$ en el antiguo Egipto (Galán 2002: 13-19).

En la inscripción que mandó grabar la reina Hatshepsut (ca.1470 a. C.) sobre la base de uno de los obeliscos que flanqueaban la entrada al templo de Karnak, se asume que el receptor del mensaje escrito pertenece al futuro y que el receptor se cuestionará la veracidad de los hechos transmitidos (Sethe 1930: 364, 365, 368):

El rey en persona dice: "Yo (lo) he colocado delante de los fieles, los que existirán en el futuro, aquellos cuyos corazones pasarán por este monumento que yo he hecho para mi padre (el dios Amón), aquellos cuyas palabras resonarán, los que presencien el porvenir [...]. Mi corazón estaba entonces anticipándose, consideran-

${ }^{12}$ Habiendo puesto en duda la veracidad de los hechos narrados en una fuente histórica, el "historiador secundario" (del que no nos han quedado noticias en el antiguo Egipto) buscaría otras fuentes de información para corroborar los hechos expuestos, o buscaría indicios dentro de la propia fuente que sirvieran para discernir la "verdad" de la "ficción". 
do las palabras de la gente, de los que verán mi monumento tras (muchos) años, de los que hablarán sobre lo que yo he hecho. Guardáos de decir: 'No lo sé, no sé por qué se ha hecho esto' [...]. Tanto el ignorante como el sabio lo saben. Y el que escuche esto que no diga que es mentira lo que yo he dicho, sino que diga: 'Cuán exacto es esto, cuán verdad es, delante de su padre (Amon)'».

En un pasaje de los famosos "anales" de Tutmosis III, incluso se le indica al lector a dónde puede acudir para verificar lo anteriormente expuesto o para conocer más detalles. Refiriéndose al tributo que su tropa había recaudado de los vasallos del faraón en Siria-Palestina, el texto dice (Sethe 1930: 693) que:

era más numeroso que cualquier otra cosa que la tropa de Su Majestad hubiera conocido, sin mentir. En efecto, está registrado en el diario del palacio real. No se ha incluido su relación en esta inscripción para no multiplicar las palabras...

La veracidad de los hechos narrados en una inscripción no sólo estaba avalada por la insistencia del rey (o del particular en el caso de una autobiografía), sino que al estar ubicada la inscripción en un espacio sagrado como es el templo (o puede ser una tumba), la divinidad allí residente garantizaba que todo lo escrito en su residencia era cierto. Así se refleja en una inscripción de Tutmosis III grabada en la cara interior del pilono VI de Karnak (Sethe 1930: 693):

No he pronunciado una proclamación para alardear de lo que he realizado, y decir que he hecho un asunto cuando Mi Majestad (en realidad) no lo ha hecho. No he actuado para la gente, y (para que) ello sea proclamado, sino que he realizado esto para mi padre [el señor de los dioses... Él no pasa por alto el que] se mencione un asunto que no se haya hecho, puesto que él conoce el cielo y conoce la tierra, y observa la tierra entera a la hora. Juro, como que Ra me ama, mi padre Amón me favorece y mi nariz inhala vida y autoridad, que yo he realizado esto [de verdad...]

Dicho esto, podemos plantearnos un problema de cierta importancia dentro de la disciplina de la Historia Antigua: la ausencia de historiografía en el antiguo Egipto, la ausencia de una narración del pasado que reconstruya hechos o situaciones a partir de la utilización crítica y contrastada de fuentes de información. La historiografía nace supuestamente en Grecia y se considera como una muestra más del avance que supone la civilización griega, la denominada "cultura clásica" por los europeos al norte del Mediterráneo. Si en efecto esto es así, cabe preguntarse por qué en Egipto no surgió esta disciplina y por qué sí en Grecia. Si el hombre funciona e innova movido en gran medida por estímulos o sentimientos de necesidad, como creo que así es, podría formularse la hipótesis de que el hombre y la sociedad del antiguo Egipto no necesitaba de la historiografía. ¿Por qué no se necesitaba de la historiografía 
en el antiguo Egipto? Una solución a este enigma podría ser que la sociedad egipcia vivía rodeada de fuentes históricas, de relatos del pasado cuya veracidad era rápidamente ratificada por elementos internos del texto (aseveraciones y juramentos por parte del autor sobre la veracidad de lo expuesto) y por elementos externos al texto (el contexto sagrado en el que se ubicaban). Para reconstruir el pasado, el hombre egipcio sólo tenía que leer las inscripciones en los templos o en las tumbas.

\section{HISTORIA Y FICCIÓN}

El pasado que los antiguos egipcios se esforzaban en mantener vivo en su memoria no sólo consistía en recordar la sucesión de los reyes de Egipto o en cuidar más o menos celosamente (según las épocas) sus monumentos más significativos, sino que consistía también, por ejemplo, en preservar el modo de conducir los rituales, la forma de elaborar las estatuas, y en transmitir a las generaciones venideras las más prestigiosas obras literarias y sus autores. El conocimiento de la cultura del pasado era para los antiguos egipcios el síntoma más claro de la cultura de una persona y de una sociedad en el presente.

Un relieve proveniente de una tumba en Saqqara de la dinastía XIX muestra una sucesión de personajes memorables momificados $y$, junto a reyes, visires y sumos sacerdotes, se menciona a varios de los escritores clásicos: Imhotep, Kaires, Jety y Jajeperraseneb (Yoyotte 1952; Simpson 1973: 354). En el papiro Chester Beatty IV se encuentra una disquisición sobre cómo la fama literaria supera a los intentos de ser recordado a través del tiempo mediante monumentos, o teniendo descendencia ${ }^{13}$. El autor menciona los nombres de escritores clásicos, cuya memoria no había caído en el olvido (Gardiner 1935: 38-39; Galán 2000: 6-7).

En cuanto a los escritores famosos desde los tiempos justo después de los dioses, los que anunciaron lo que iba a suceder, sus nombres permanecen para la eternidad. Habiéndose marchado, habiendo completado sus vidas, todo su linaje ha sido olvidado. Ellos no se hicieron para sí tumbas de cobre, con estelas de metal celeste. No supieron dejar descendencia en hijos [suyos] que pronunciaran sus nombres. Ellos crearon para sí descendencia en libros con las enseñanzas que ellos compusieron [...].

Un hombre fallece y su cuerpo está en el suelo, toda su estirpe ha sido traída a la tierra. El libro es lo que hace que él sea recordado en boca de los oradores. Más beneficioso es una obra escrita que una casa construida, que una capilla en el Occidente; es mejor que un caserón, que una estela en un templo.

\footnotetext{
${ }^{13}$ Museo Británico 10684, verso 2, 5-9; 3, 3-8.
} 
¿Es que acaso hay alguien aquí como Hordedef? ¿Hay algún otro como Imhotep? No ha surgido nadie en nuestra estirpe como Neferty, ni como Jety, el mejor de ellos. Haré que conozcas el nombre de Ptahemyehuty, el de Jajeperraseneb. ¿Hay otro como Ptahhotep, o como Kaires? Aquellos que sabían anunciar lo que vendría, lo que salía de sus bocas ocurría y se encuentra fijado por escrito en sus obras.

Las composiciones de ficción, al igual que las inscripciones con fines políticos, recurren al pasado para aludir a una situación presente o influir sobre una determinada audiencia contemporánea. También los textos literarios reconstruyen y moldean el pasado para adaptarlo a las necesidades del autor y conseguir sus objetivos. Uno de los textos "clásicos" más copiados en el antiguo Egipto, obra de uno de los autores recordados en el papiro Chester Beatty IV, es la denominada Profecía de Neferty, que utiliza, a la manera de Shakespeare, a un rey legendario del pasado —quien había vivido unos quinientos años antes - para aludir de forma alegórica a la situación que se estaba viviendo por entonces en el país ${ }^{14}$. El texto comienza de la siguiente manera (Helck 1970: 3-15; Galán 2000: 7-8):

Ocurrió cuando la majestad del rey de Egipto Seneferu - (santo) inocente- era rey benefactor en la tierra entera. Uno de esos días, entraron los magistrados de la Residencia a palacio a saludar. Salieron, habiendo saludado de acuerdo con su costumbre diaria.

Su Majestad dijo entonces al portador del sello que estaba a su lado: "Ve y tráeme a los magistrados de la Residencia que acaban de salir de aquí, de saludar hoy". Fueron traídos inmediatamente y se postraron ante Su Majestad otra vez. Su Majestad les dijo:

- iCamaradas! Os he mandado llamar para que me busquéis a un hijo vuestro que sea sabio, a un hermano que sea excelso, a un compañero que realice algo notable, alguien que me cuente algo interesante ${ }^{15}$, un discurso escogido que al escucharlo entretenga a Mi Majestad.

Ellos se postraron de nuevo ante Su Majestad y le dijeron:

- Hay un gran sacerdote lector de Bastet, oh soberano, nuestro señor, cuyo nombre es Neferty. Es un hombre de valeroso brazo, un escriba de hábiles dedos, un magnate rico como ningún otro. Que sea traído para que Su Majestad le vea. Su Majestad dijo entonces:

-Id y traédmelo.

Fue traído inmediatamente. Él se postró ante Su Majestad. Su Majestad dijo:

—iOh Neferty, compañero! cuéntame algo interesante, un discurso escogido que al escucharlo entretenga a Mi Majestad.

—iAlgo que ha ocurrido, o algo que ocurrirá? Oh soberano, mi señor.

-Algo que ocurrirá. Hoy ya se ha pasado.

(El rey) estrechó su mano hasta un estuche de escritura, tomó un rollo de papiro y una paleta, y puso por escrito lo que el sacerdote lector Neferty decía.

\footnotetext{
${ }^{14}$ Papiro San Petesburgo 1116B, 1-17.

${ }^{15}$ El compuesto mdwt nfrwt es frecuentemente interpretado como el equivalente egipcio para referirse a las "belles lettres."
} 
Seneferu fue un rey que pronto se ganaría la reputación de benefactor para Egipto. Su buena fama llegaría incluso hasta tiempos de Heródoto. Una suerte contraria sufriría el rey Keops, constructor de la gran pirámide de Giza, quien se granjearía la fama de rey déspota, muy probablemente por las exageradas dimensiones de su monumento funerario. Uno de los cuentos del denominado Papiro Westcar ${ }^{16}$ relata cómo el sabio y mago Yedi, extraído de su entorno humilde y rural por el príncipe Hordedef, es presentado ante Keops para entretenerle con sus conocimientos (de Buck 1948: 82-85; Blackman 1988: 11-14; Goedicke 1993: 23-36; Galán 2000: 31-34):

Cuando Yedi fue presentado, Su Majestad dijo: -Yedi, ¿cómo es que nunca te he visto (antes)?

-Quien es llamado, oh rey, mi señor, es quien viene (a ti). Cuando yo he sido llamado, yo he venido.

—Es verdad lo que dicen, que puedes unir una cabeza cortada?

- Sí, puedo hacerlo, oh rey, mi señor.

-Que me traigan a un prisionero de la cárcel y que sea ejecutado.

- (a lo que contestó Yedi:) Pero no a una persona, oh rey, mi señor. No está permitido hacer algo así al rebaño (más) distinguido.

Entonces, fue traído un ganso y se le cortó la cabeza. Se colocó al ganso en el lado oeste del patio y su cabeza en el lado este del patio. Yedi pronunció sus palabras mágicas, el ganso se levantó y avanzó, y también lo hizo su cabeza. Cuando se unieron, el ganso graznó. (Luego) trajeron un ave mayor, y lo mismo hizo con ella. Su Majestad hizo que le trajeran un buey y que se le cortara la cabeza. Yedi pronunció sus palabras mágicas y el buey se levantó [...].

De igual forma que en los textos literarios se utilizan momentos concretos del pasado como un recurso para potenciar o realzar el mensaje que con el relato pretendía transmitir su autor (Björkman 1964, Posener 1969), también las inscripciones conmemorativas, que pretendían convertirse en fuentes históricas, utilizan el pasado para alcanzar un fin concreto en el presente o en el futuro próximo. Este es el caso de la denominada "estela de la princesa de Bakhtan" o "estela de Bentresh" ${ }^{17}$, escrita en Época Persa o Ptolemaica pero cuyo autor hace transcurrir la acción bajo el reinado de Ramsés II (Morschauser 1988; Broze 1989; Lichtheim 1973-1980: III, 90-94). Otra inscripción "pseudoepigráfica" es la denominada "estela del hambre", grabada sobre una roca en la isla de Sehel, en la Primera catarata, y cuyo protagonista es el rey Zoser de la dinastía III, a pesar de que el texto se escribiera en Época Ptolemaica (Barguet 1953; Goedicke 1994; Lichtheim 1973-1980: III, 94-103). El texto pretende retrotraer hasta un monarca legendario la conce-

\footnotetext{
${ }^{16}$ Papiro Berlín 3033: 9, 1- 11, 3.

${ }^{17}$ Louvre C.284. La estela fue hallada entre ruinas de época greco-romana, junto al templo de Jonsu en Karnak.
} 
sión de importantes donaciones y privilegios al templo de Jenum en la vecina isla de Elefantina.

Como en tantos otros aspectos relacionados con la sociedad, con la cultura y con las mentalidades, los textos del antiguo Egipto desarrollan todo tipo de "juegos" entre lo que supuestamente es parte de la realidad (historia) y lo que es ficción (mito y literatura), desdibujando la línea divisoria entre ambas categorías en principio antagónicas. Sus esfuerzos por reconstruir el pasado y su utilización para la consecución de unos fines concretos en el presente o en el futuro próximo nos muestra cómo el antiguo Egipto sigue estando muy próximo a nosotros, formando parte de nuestra cultura.

\section{BIBLIOGRAFÍA CITADA}

ASSMANN, JAN. 1983. "Schrift, Tod und Identität: das Grab als Vorschule der Literatur im alten Ägypten", en J. Assmann et al (eds.), Schrift und Gedächnis: 64-93. Munich: Wilhelm Fink Verlag.

BAINES, JOHN. 1989. "Ancient Egyptian Concepts and Uses of the Past: 3rd to 2nd Millennium BC Evidence", en R. Layton (ed.), Who Needs the Past? Indigenous Values and Archaeology: 131-49. Londres: Unwin Himan.

BARguet, PIERre. 1953. La stèle de la famine à Sébel. El Cairo: Institut Française d'Archéologie Orientale.

BJörkMAN, Gun. 1964. "Egyptology and Historical Method". Orientalia Suecana 13: 9-33.

BlACKMAN, AYLWARD. 1988. The Story of King Kheops and the Magicians. Whitstable: J.V. Books.

BROZE, MiCHĖLE. 1989. La princesse de Bakhtan. Bruselas: Fondation Égyptologique Reine Élisabeth.

BUCK, ADRIAN DE. 1948. Egyptian Reading Book. Leiden: Nederlandsch ArchaeologischPhilologisch Instituut voor het Nabije Oosten.

Demaré, ROBERT. 1983. The 3h ikr $n$ R'-Stelae on Ancestor Worship in Ancient Egypt. Leiden: Nederlands Instituut voor het Nabije Oosten.

DIEGO ESPINEL, ANDRÉS. 2004. Etnicidad y territorialidad durante el Reino Antiguo. Barcelona: Aula Aegyptiaca.

DREYER, GÜNTER. 1987. "Ein Siegel der Frühzeitlichen Königsnekropole von Abydos". Mitteilungen des Deutschen Archäologischen Instituts Abteilung Kairo 43: 33-43.

EYRE, CHRISTOFER. 1990. "The Semna Stelae: Quotation, Genre and Functions of Literature", en S. Israelit-Groll (ed.), Studies in Egyptology Presented to Myriam Lichtheim, I: 13465. Jerusalén: The Magnes Press.

Galán, JosÉ MANUEL. 2000. Cuatro Viajes en la Literatura del Antiguo Egipto. Madrid: CSIC.

-. 2002. El imperio egipcio. Inscripciones, ca. 1500-1300 a.C. Madrid: Trotta.

GARDINER, ALAN. 1935. Hieratic Papyri in the British Museum, Third Series: Chester Beatty Gift, I. Londres: British Museum.

- 1959. The Royal Canon of Turin. Oxford: Griffith Institute.

GNIRS, ANDREA. 1996. "Die Ägyptische Autobiographie", en A. Loprieno (ed.), Ancient Egyptian Literature: History and Forms: 191-241. Leiden: Brill. 
GoEdicke, Hans. 1993. "Thoughts about the Papyrus Westcar". Zeitschrift für Ägyptische Sprache 120: 23-36.

-. 1994. Comments on the 'Famine Stela'. San Antonio: Van Siclen Books.

HelcK, WolfGang. 1955. Urkunden der 18. Dynastie. Berlín: Academie Verlag.

- 1970. Die Prophezeiung des Nfr.tj. Wiesbaden: Otto Harrassowitz.

- 1975. Historisch-biographische Texte der 2. Zwischenzeit und Neue Texte der 18. Dynastie. Wiesbaden: Otto Harrassowitz.

—. 1977. Die Lebre für König Merikare. Wiesbaden: Otto Harrassowitz.

HORNUNG, ERIK. 1982. Der Ägyptische Mythos von der Himmelskub: eine Ätiologie des Unvollkommenen. Friburgo: Universitatsverlag Freiburg Schweiz.

JANSSEN, JosSEF. 1953. "The Stela (Khartoum Museum no. 3) from Uronarti". Journal of Near Eastern Studies 12: 51-55.

KeMP, BARRY. 1989. Ancient Egypt: Anatomy of a Civilization. Nueva York: Routledge.

LACAU, PIERRE, Y JEAN LAUER. 1959-61. La pyramide à degrés, IV. El Cairo: Institut Française d'Archéologie Orientale.

LePSIUS, RICHARD. 1849-1859. Denkmaeler aus Aegypten und Aetbiopien. Berlín: Nicolaische Buchhandlung.

Lichtheim, Miriam. 1973-1980. Ancient Egyptian Literature. Berkeley: University of California Press.

MAYstre, Charles. 1941. "Le livre de la Vache du Ciel dans les tombeaux de la Vallée des Rois". Bulletin de l'Institut Française d'Archéologie Orientale 40: 53-115.

MORSCHAUSER, SCHOTT. 1988. "Using History: Reflections on the Bentresh Stela". Studien zur Altägyptischen Kultur 15: 203-223.

PARKINSON, RICHARD. 1991. Voices from Ancient Egypt: an Anthology of Middle Kingdom Writings. Oklahoma: University of Oklahoma Press.

POSENER, GEORGES. 1969. Littérature et politique dans l'Égypte de la XIIe dynastie. París: Librairie Honoré Champion.

QUACK, JOACHIM. 1992. Studien zur Lebre für Merikare. Wiesbaden: Otto Harrassowitz.

REDFORD, DONALD. 1986. Pharaonic King-Lists, Annals and Day-Books: A Contribution to the Study of the Egyptian Sense of History. Mississauga: Benben Publications.

SCHOTT, SIGFRIED. 1990. Bücher und Biblioteken im alten Ägypten. Verzeichnis der Buchund Sprucbtitel und der Termini Technici. Wiesbaden: Otto Harrassowitz.

SERRANO, JosÉ Miguel. 2001. "El eterno retorno en el antiguo Egipto", en J. Mangas y S. Montero (eds.), El milenarismo. La percepción del tiempo en las culturas antiguas: 1-23. Madrid: Universidad Complutense de Madrid.

SETHE, KURT. 1930. Urkunden der 18. Dynastie, III. Leipzig: J.C. Hinrichs'sche Buchhandlung.

-. 1933. Urkunden des Alten Reichs. Leipzig: J.C. Hinrichs'sche Buchhandlung.

SimPSON, WILliam. 1973. The Literature of Ancient Egypt. New Haven: Yale University Press.

VERnUS, PASCAL. 1995. Essai sur la conscience de l'Histoire dans l'Egypte pharaonique. París: Librairie honoré Champion.

Wilkinson, TоBy. 2000. Royal Annals of Ancient Egypt: the Palermo Stone and its Associated Fragments. Londres: Kegan Paul International.

YOYOTTE, JEAN. 1952. "A propos d'un monument copié par G. Daressy: Contribution à l'histoire littéraire". Bulletin de la Société Française d'Égyptologie 11: 67-72. 